\title{
Demographic and Socioeconomic Factors of Patients With Coronary Artery Diseases Undertreatment of Coronary Artery Bypass Grafting, Percutaneous Coronary Intervention and Drug Therapy in Mashhad, Iran
}

\author{
Maryam Mirzaie ${ }^{1}$; Mohammad Khajedaluee ${ }^{1, *}$; Homa Falsoleiman ${ }^{2}$; Asadollah Mirzaie ${ }^{3}$; \\ Mehdi Reza Emadzadeh ${ }^{2}$; Majid Reza Erfanian Taghvaei ${ }^{1}$ \\ ${ }^{1}$ Department of Community Medicine, Faculty of Medicine, Mashhad University of Medical Sciences, Mashhad, IR Iran \\ ${ }_{3}^{2}$ Department of Cardiology, Mashhad University of Medical Sciences, Mashhad, IR Iran \\ ${ }^{3}$ Department of Cardiac Surgery, Mashhad University of Medical Sciences, Mashhad, IR Iran \\ ${ }^{*}$ Corresponding Author: Mohammad Khajedaluee, Department of Community Medicine, Faculty of Medicine, Mashhad University of Medical Sciences, Mashhad, IR Iran. \\ Tel: +98-5138828888, Fax: + 98-513828560, E-mail: khajedalueem@mums.ac.ir \\ Received: February 24, 2015; Revised: April 4, 2015; Accepted: April 14, 2015
}

\begin{abstract}
Background: Considering the importance of preventing cardiovascular diseases, determining the contributing risk factors for ischemic heart disease which leads to atherosclerotic plaque, could be effective in selecting the required interventions.

Objectives:This study aimed to evaluate socioeconomic factors in patients with Coronary Artery Diseases(CAD) in three treatment groups: Coronary Artery Bypass Grafting (CABG), Percutaneous Coronary Intervention (PCI) and drug therapy. By identifying and comparing the underlying factors in treatment groups, we can gather useful information for future planning and policy making in order to reduce and eliminate the contributing factors.

Patients and Methods: This cross-sectional study was conducted on 760 patients with CAD referred to cardiovascular health centers in Mashhad, Iran, including Javad-Al-Aeme Heart Hospital, Qaem, Imam Reza and Dr. Shariati educational Hospital. Samples were collected through purposive sampling from January to March 2014. Based on the experts' opinion, the subjects were categorized into three treatment groups: $\mathrm{CABG}, \mathrm{PCI}$, and drug therapy.

Results: The mean age of total patients was $58.3 \pm 11.5$ years $(\mathrm{P}=0.09)$. The proportion of rural patients in the $\mathrm{PCI}(26.7 \%)$ and drug therapy (27.5\%) groups was twice as high as the CABG group $(11.7 \%)(\mathrm{P}<0.001)$. The proportion of patients with higher educational level(higher than high school diploma) in the CABG group (35.9\%) was higher than PCI and drug therapy groups $(26.7 \%, 24.3 \%)(\mathrm{P}=0.006)$. Smoking, drinking and drug abuse were more common in the drug therapy group $(\mathrm{P}=0.03, \mathrm{P}=0.02$, and $\mathrm{P}<0.001$, respectively). One-vessel and three-vessel coronary artery diseases were more common in the drug and CABG groups, respectively $(\mathrm{P}<0.001)$.

Conclusions: In total, application of therapeutic approaches in patients with CAD depends on many factors. In our study not only risk factors such as gender, lifestyle, smoking, alcohol abuse, diabetes and hypertension were associated with the incidence of CAD, but also they were highly correlated with the severity of the disease.
\end{abstract}

Keywords: Socioeconomic Factors; Coronary Artery Disease; Coronary Artery Bypass Grafting; Percutaneous Coronary Intervention; Drug Therapy

\section{Background}

The prevalence of noncommunicable diseases is rising rapidly in many countries due to factors such as increased life expectancy, increased exposure to risk factors and changes in lifestyle (1). In 1990, in terms of the global burden of diseases, noncommunicable diseases were placed among the first fifteen ranks (2). As the statistical estimations have revealed, these conditions will rise among the first six ranks by $2020(1,2)$.

Atherosclerosis, which is among the most important global health concerns, is a slow progressive disease. This condition occurs due to the thickening of coronary arteries. Annually, more than 900 thousand deaths occur in the US due to cardiovascular diseases, and three-quarters of these diseases are associated with Coronary Artery Disease (CAD) (3). In Iran, cardiovascular diseases, especially $\mathrm{CAD}$, are the first and most common cause of mortality in men and women $(3,4)$.

The treatment costs of cardiovascular diseases imposed on individuals and society are substantial. In the coming years, these conditions will affect a vast majority of work-

Copyright ( 2015, Iranian Red Crescent Medical Journal. This is an open-access article distributed under the terms of the Creative Commons Attribution-NonCommercial 4.0 International License (http://creativecommons.org/licenses/by-nc/4.0/) which permits copy and redistribute the material just in noncommercial usages, provided the original work is properly cited. 
ing population in developing countries; therefore, cardiovascular diseases are expected to be a heavy financial burden on developing countries (5).

Current knowledge indicates that the prevention of cardiovascular diseases, based on the determining factors, requires a set of interventions. In cases such as smoking, these interventions must anticipate the medical and social needs of cardiac patients in relation to their family and community (3).

In the past, the only way to prevent early morbidity and mortality, associated with cardiovascular diseases, was the third level of prevention. However, today, through recognizing the contributing risk factors such as urbanization, poor diet, economic status, air pollution, physical inactivity, mental stress, and smoking, we can promote public health by focusing on primary prevention, lifestyle changes, and elimination of risk factors for cardiac diseases (6).

\section{Objectives}

Among previously performed studies in Iran and other countries, the present research is admittedly the first study on CADs, which aimed to evaluate demographic and socioeconomic factors in three treatment groups: Coronary Artery Bypass Grafting (CABG), Percutaneous Coronary Intervention (PCI) and drug therapy. By identifying and comparing the underlying factors, we can gather useful information for future planning and policy making to reduce and eradicate the contributing factors.

\section{Patients and Methods}

This cross-sectional study was conducted on 760 patients with CAD referred to cardiovascular referral health centers in Mashhad, the north east of Iran, including general, governmental, educational, clinical and paraclinical Hospitals named Qaem with 780 beds, Imam Reza with 918 beds, Dr. Shariati with 300 beds and also Javad-al-Aeme, the specialized and referral private heart center with 460 beds. These centers provide health care for most patients with cardiovascular diseases in Mashhad; therefore, they are good representatives of the population with cardiovascular diseases.

Samples were collected using purposive sampling. All cases with CAD referred to cardiovascular health centers in Mashhad from January to March 2014 were considered to be as a study sample and were followed. The cases were categorized based on the treatment diagnosis made by cardiologists and cardiac surgeons into three treatment groups: $\mathrm{CABG}, \mathrm{PCI}$ and drug therapy.

The inclusion criteria were diagnosis of CAD and age range of 35-70 years. The exclusion criteria were as follows: 1 ) ejection fraction $<35 \%$ on echocardiography; 2 ) prior history of other conditions such as renal diseases, peripheral arterial occlusive disease, mobility problems, chronic obstructive pulmonary disease, and mental dis- orders; and 3) previous bypass surgery. The sample size of 250 patients in each group at baseline with the formula of Equation 1 was considered.

$$
n=\frac{\left(z_{1}-\frac{\alpha}{2}+z_{1}-\beta\right)^{2}\left(\sigma_{1}^{2}-\sigma_{2}^{2}\right)}{\left(\mu_{1}-\mu_{2}\right)^{2}}
$$

At the march 2014, we got the study sample consisted of 760 individuals, including 251 cases in the drug therapy group, 236 patients in the PCI group and 273 patients in the CABG group. Economic, social, demographic and clinical data including age, sex, Body Mass Index (BMI), prior myocardial infarction, and previous coronary angiography were extracted from patients' medical records using a checklist. This checklist was created by a joint panel of cardiologists, cardiac surgeons and community medicine specialists for the accuracy and precision of the equipment. A nurse practitioner with an advanced coursework in cardiac diseases completed the information of the checklist.

The patients were enrolled in the study after obtaining informed consents. This study was approved by the ethics committee of Mashhad University of Medical Sciences (approval code: 920375).

\subsection{Statistical Analysis}

Data were analyzed by SPSS version 11.5. (SPSS Inc., Chicago, IL, USA) Characteristics of the three groups were expressed using descriptive statistics, central tendency and dispersion that were presented as mean, median, variance, and standard deviation. The chi-square test was used to compare qualitative variables. Assessment of the data normality was done by SPSS. ANOVA test was used to compare normal quantitative variables between the groups and to determine whether there are any significant differences among the means of three independent groups. For the data that meet the assumption of homogeneity of variances, Tukey's Honestly Significant Difference (HSD) post-hoc tests were used and for the data did not meet the assumption of homogeneity of variances, the Dunnett's C post-hoc tests were considered. The Kruskal-Wallis test was used for continuous or ordinal dependent variables among the groups. In all calculations, $P$ value less than 0.05 was considered statistically significant.

\section{Results}

Socioeconomic and demographic characteristics of the study population are presented in Table 1 . From a total of 760 patients, 236 (31\%), 273 (36\%), and $251(33 \%)$ patients were treated by PCI, CABG and drug therapy, respectively. The mean age of patients was $11.5 \pm 58.3$ years, which was not significantly different among the three groups $(\mathrm{P}=0.09)$. 
Mirzaie $M$ et al.

\begin{tabular}{|c|c|c|c|c|c|}
\hline \multirow[t]{2}{*}{ Characteristics } & \multicolumn{3}{|c|}{ Treatment Group } & \multirow[t]{2}{*}{ Total $(N=760)$} & \multirow[t]{2}{*}{ PValue } \\
\hline & $\operatorname{PCI}(\mathrm{N}=236)$ & $\mathrm{CABG}(\mathrm{N}=273)$ & Drug Therapy $(\mathrm{N}=\mathbf{2 5 1})$ & & \\
\hline Age, $y$ & $11.41(57.59)$ & $59.55(10.34)$ & $57.65(12.60)$ & $58.3(11.5)$ & $0.09^{c, d}$ \\
\hline Gender & & & & & $<0.001 \mathrm{e}^{\mathrm{e}}$ \\
\hline Male & $130(55.1)$ & $186(68.1)$ & $131(52.2)$ & $447(58.8)$ & \\
\hline Female & $106(44.9)$ & $87(31.9)$ & $120(47.8)$ & $313(41.3)$ & \\
\hline Residence status & & & & & $<0.001^{\mathrm{e}}$ \\
\hline Urban & $173(73.3)$ & $241(88.3)$ & $182(72.5)$ & $596(78.4)$ & \\
\hline Rural & $63(26.7)$ & $32(11.7)$ & $69(27.5)$ & $164(21.6)$ & \\
\hline Marital status & & & & & $0.06^{\mathrm{e}}$ \\
\hline Married & $211(89.4)$ & $208(76.2)$ & $220(87.6)$ & $639(84.1)$ & \\
\hline Single & $2(0.9)$ & $32(11.7)$ & $9(3.6)$ & $43(5.6)$ & \\
\hline Widowed or divorced & $23(9.7)$ & $33(12.1)$ & $22(8.8)$ & $78(10.3)$ & \\
\hline Educational level & & & & & $0.006^{\mathrm{f}}$ \\
\hline Lower than high school diploma & $173(73.3)$ & $175(64.1)$ & $190(75.7)$ & $538(70.8)$ & \\
\hline High school diploma and higher & $63(26.7)$ & $98(35.9)$ & $61(24.3)$ & $222(29.2)$ & \\
\hline Occupational status & & & & & $<0.001^{\mathrm{e}}$ \\
\hline Unemployed & $54(22.9)$ & $103(37.7)$ & $60(23.9)$ & $217(28.6)$ & \\
\hline Employee & $88(37.3)$ & $87(31.9)$ & $80(31.9)$ & $255(33.5)$ & \\
\hline Housewife & $94(39.8)$ & $83(30.4)$ & $111(44.2)$ & $288(37.9)$ & \\
\hline Insurance coverage & & & & & $0.008^{\mathrm{e}}$ \\
\hline Yes & $185(78.4)$ & $250(91.6)$ & $225(89.6)$ & $660(86.9)$ & \\
\hline No & $15(6.4)$ & $3(1.1)$ & $17(6.8)$ & $35(4.6)$ & \\
\hline Supplemental insurance & $36(7.3)$ & $20(7.3)$ & $9(3.6)$ & $65(8.5)$ & \\
\hline BMI, $\mathrm{kg} / \mathrm{m}^{2}$ & $25.73(2.92)$ & $26.18(3.45)$ & $26.30(3.85)$ & $26.07(3.43)$ & $0.181 \mathrm{~g}$ \\
\hline Monthly income of patients, USD ${ }^{h}$ & $238.15(135.67)$ & $277.67(157.4)$ & $266.39(169.83)$ & $255.56(154.81)$ & $0.561^{\mathrm{i}}$ \\
\hline Smoking & $39(16.6)$ & $94(34.5)$ & $78(31.1)$ & $211(27.7)$ & $<0.001^{\mathrm{e}}$ \\
\hline Alcohol & $2(0.8)$ & $6(2.2)$ & $12(4.8)$ & $20(2.6)$ & $0.02^{\mathrm{e}}$ \\
\hline Narcotic and drug & $17(7.2)$ & $28(10.2)$ & $37(14.7)$ & $82(10.8)$ & $0.03^{\mathrm{e}}$ \\
\hline Diabetes & $63(26.7)$ & $169(61.9)$ & $153(60.7)$ & $385(50.7)$ & $0.05^{\mathrm{e}}$ \\
\hline Hypertension & $130(55.1)$ & $127(46.5)$ & $138(55)$ & $395(52)$ & $0.21 \mathrm{e}$ \\
\hline $\begin{array}{l}\text { The number of affected coronary } \\
\text { arteries } j\end{array}$ & & & & & $<0.001^{\mathrm{f}}$ \\
\hline One & $15(23.9)$ & $4(4.3)$ & $81(35.8)$ & $100(26.1)$ & \\
\hline Two & $22(34.9)$ & $13(13.8)$ & $84(37.2)$ & $119(31.1)$ & \\
\hline Three & $26(41.2)$ & $77(81.9)$ & $61(27)$ & $164(42.8)$ & \\
\hline $\begin{array}{l}\text { a Abbreviations: BMI, body mass index } \\
\text { b The numbers in the table are expres } \\
\text { c Analysis by ANOVA. } \\
\text { d Post hoc test between groups } P>0 \text {. } \\
\text { e Analysis by chi-square test. } \\
\text { f Analysis by the Kruskal Wallis test. } \\
\text { g Post hoc test between groups } P>0.0 \\
\text { h Iranian rial currency exchange rate } \\
\text { i Post hoc test between groups } P>0.0 \\
\text { j Among } 760 \text { patients, } 383 \text { cases of cor }\end{array}$ & $\begin{array}{l}\text { ercutaneous cor } \\
\text { hean (SD) or No. } \\
\text { the dollar cons }\end{array}$ & $\begin{array}{l}\text { ed by an average } \\
\text { termined. }\end{array}$ & $\begin{array}{l}\text { CABG, coronary artery by } \\
\text { f variable. } \\
26500 \text { rial equal one US do }\end{array}$ & s graft. & \\
\hline
\end{tabular}

Regarding the gender distribution, $59 \%$ of the subjects were male and $41 \%$ were female. In terms of gender distribution in the three groups, the number of women was higher in the drug therapy and PCI groups compared to the CABG group ( $47.8 \%$ and $44.9 \%$ vs. $31.9 \%$ ); the difference was statistically significant $(\mathrm{P}<0.001)$.

In total, $77.8 \%$ of the studied patients were urban residents and $22.2 \%$ were residing in rural areas. In terms of rural population distribution in the three groups, the ratio of rural subjects to urban patients in the drug therapy and PCI groups was twice as high as the CABG group (27.5\% and $26.7 \%$ vs. $11.7 \%$ ); also, the difference was statistically significant $(\mathrm{P}<0.001)$.
In terms of marital status, although the CABG group was twice higher than two other treatment groups in single patients, the difference was statistically insignificant $(\mathrm{P}=0.06)$. Distribution of patients' educational level in the drug therapy and PCI groups was nearly identical. However, the proportion of the patients with a higher educational level in the CABG group was about 1.5 times higher than other groups; this difference was statistically significant $(\mathrm{P}=0.006)$. In terms of occupational status, proportion of housewives in the drug therapy and PCI groups was significantly higher than the CABG group $(\mathrm{P}=0.05)$.

In terms of health insurance coverage, lack of the insur- 
ance coverage in the drug therapy and PCI groups was twice as common as the CABG group. Also, supplemental insurance coverage in the CABG and PCI groups was more than twice as common as the drug therapy group; these differences were statistically significant $(\mathrm{P}=0.008)$. The mean BMI in three treatment groups indicated overweight, although no significant difference was observed among the three groups $(\mathrm{P}=0.18)$. Moreover, no significant difference was observe in a monthly income among the three groups $(\mathrm{P}=0.56)$.

In total, $27.2 \%$ of the patients smoked cigarettes. Smoking in the drug therapy and CABG groups was twice as common as the PCI group and the difference was statistically significant. Overall, $2.4 \%$ of patients consumed alcohol and 10.6\% used drugs. Alcohol and drug abuse in the drug therapy group was about twice as common as the PCI and CABG groups; the difference was also statistically significant $(\mathrm{P}=0.02$ and $\mathrm{P}=0.03$, respectively).

Moreover, $51 \%$ of the patients had a prior history of diabetes. Diabetes in the drug therapy and CABG groups was significantly more common than the PCI group (twice as common $)(\mathrm{P}=0.05)$. Also, $52 \%$ of patients reported no prior history of hypertension. However, hypertension in the three treatment groups was not significantly different $(P=0.21)$.

As can be seen in Table 1, among 760 patients, 383 cases of coronary involvement were determined by angiography. One-vessel CAD in the drug therapy group was more common than the other two groups. On the other hand, three-vessel CAD was more prevalent in the CABG group compared to other treatment groups. The number of affected vessels was significantly different between the three groups $(\mathrm{P}<0.001)$.

The number of involved vessels is presented in Table 2, based on patients' clinical and demographic characteristics. The prevalence of one-vessel CAD was similar in female and male patients. However, two- and threevessel $\mathrm{CAD}$ in male patients was more common than female patients; the difference was statistically significant $(P=0.02)$. Distribution of the number of affected coronary arteries in rural patients was significantly different from that reported in urban patients. In fact, three-vessel CAD was less common than one- or two-vessel CAD in rural patients $(\mathrm{P}=0.005)$. However, no significant relationship was observed between the number of affected coronary arteries and BMI or economical status $(\mathrm{P}=0.17$ and $\mathrm{P}=0.37$, respectively). Although the prevalence of three-vessel CAD was higher in smokers, the difference was not statistically significant $(\mathrm{P}=0.16)$. Also, alcohol abuse was not significantly different between patients with different types of CAD $(P=0.07)$. Drug abuse in patients with one-vessel CAD was significantly more prevalent than patients with two- or three-vessel CAD $(P=0.03)$. As presented in Table 2, increased number of affected vessels was correlated with the incidence of diabetes and hypertension $(\mathrm{P}=0.001$ and $\mathrm{P}<0.001$, respectively).

\begin{tabular}{|c|c|c|c|c|}
\hline Characteristic & $1 \mathrm{VD}(\mathrm{N}=100)$ & $2 \mathrm{VD}(\mathrm{N}=119)$ & $3 \mathrm{VD}(\mathrm{N}=164)$ & P Value $^{\mathrm{C}}$ \\
\hline \multicolumn{5}{|l|}{ Gender } \\
\hline Female & $49(49)$ & $47(39.4)$ & $50(30.5)$ & 0.02 \\
\hline Male & $51(51)$ & $72(60.6)$ & $114(69.5)$ & \\
\hline \multicolumn{5}{|l|}{ Residence status } \\
\hline Urban & $79(79)$ & $88(74)$ & $147(89.6)$ & 0.005 \\
\hline Rural & $21(21)$ & $31(26)$ & $17(10.4)$ & \\
\hline \multicolumn{5}{|l|}{ Educational level } \\
\hline $\begin{array}{l}\text { Lower than high school } \\
\text { diploma }\end{array}$ & $74(74)$ & $89(74.8)$ & $100(61)$ & 0.005 \\
\hline $\begin{array}{l}\text { High school diploma and } \\
\text { higher }\end{array}$ & $26(26)$ & $30(25.2)$ & $64(39)$ & \\
\hline BMI, $\mathrm{kg} / \mathrm{m}^{2}$ & $26.3(3.7)$ & $27.3(4.2)$ & $26.3(3.1)$ & $0.37^{\mathrm{d}, \mathrm{e}}$ \\
\hline $\begin{array}{l}\text { Monthly income of } \\
\text { patients, USD }\end{array}$ & $344(183.77)$ & $228.11(102)$ & $298.25(166.88)$ & $0.71^{d, g}$ \\
\hline Smoking & $25(25)$ & $30(25.2)$ & $59(35.6)$ & 0.16 \\
\hline Alcohol & $7(7)$ & $15(12.6)$ & $5(3)$ & 0.07 \\
\hline Narcotic and drug & $21(21)$ & $11(9.3)$ & $20(12.1)$ & 0.03 \\
\hline Diabetes & $18(18)$ & $27(22.7)$ & $97(59.1)$ & $<0.001$ \\
\hline Hypertension & $7(7)$ & $32(26.9)$ & $33(20.1)$ & 0.001 \\
\hline \multicolumn{5}{|c|}{$\begin{array}{l}\text { a Abbreviations: BMI, body mass index; VD, vessel disease. } \\
\text { b The numbers in the table are expressed as No. (\%) or Mean (SD) based on the type of variable. } \\
\text { c Analysis by chi-square. } \\
\text { d Analysis by ANOVA. } \\
\text { e Post hoc test between groups P }>0.005 \text {. } \\
\text { f Iranian rial currency exchange rate against the dollar considered by an average of } 26500 \text { rial e }\end{array}$} \\
\hline
\end{tabular}


Mirzaie $M$ et al.

\section{Discussion}

Risk factors for ischemic heart disease can accelerate the chronic inflammatory process, which leads to atherosclerotic plaque (7). The obtained results showed that the proportion of male patients was higher in the CABG group compared to other treatment groups. Also, the subjects in the CABG group were older than those in other groups. These findings were in agreement with the results of a review study on ten trials, comparing CABG and PCI in patients with multi-vessel CAD (8).

In this study, the proportion of rural patients in the CABG group was far less than that reported in the PCI and drug therapy groups. Many factors such as the severity and type of coronary artery occlusion, urgency of treatment, physicians' medical advice, and the patient's decision contribute to the selection of a treatment method. Moreover, the decision for the preliminary treatment is influenced by disease severity, patient's general condition, and age. In addition, preference for a treatment method is dependent on hospital facilities and the patient's economic status (9). In this study, access to hospital facilities and patients' economic status affected their choice of treatment modality.

The results of this study revealed that subjects in the CABG and PCI groups were more educated than the drug therapy group (higher than high school diploma). Also, the proportion of patients with lower educational level (less than diploma) was the highest in the drug therapy group. This difference may be due to the correlation among educational level, income level and social class. In fact, patients with a high income have more access to CABG and PCI methods, which are costly modes of treatment; this could be one of the criteria for selecting the treatment method. Smith and colleagues also showed a significant relationship between education and therapeutic techniques (10).

Insurance coverage in the CABG and PCI groups was twice as common as the drug therapy group. Given the substantial costs of CABG and PCI treatments compared to drug therapy, it seems that supplemental insurance coverage plays a contributing role in choosing the treatment method. Federman and colleagues also evaluated the effect of supplemental insurance on treatment methods in patients with CAD (11). The results revealed a significant correlation between insurance coverage and effective treatment methods (11).

In this study, diabetes mellitus in the CABG group was significantly more prevalent than that reported in drug therapy group. On the other hand, the number of affected coronary arteries was significantly higher in the CABG group compared to other treatment groups. If we consider the number of affected coronary arteries as an indication of the severity of CAD, diabetes mellitus is significantly associated with the severity of CAD. The same findings were reported regarding cigarette smoking.

Several epidemiological studies have shown that dia- betes and smoking are major risk factors for $\operatorname{CAD}(4,12$, 13). Some previous studies have noted that risk of CAD in diabetic patients is three to four times higher than nondiabetic patients $(14,15)$. Kanitz and colleagues in a study, which aimed to determine the major risk factor for CAD, introduced cigarette smoking as the most important risk factor for myocardial infarction in patients younger than 40 years (16). The results showed that the number of affected coronary arteries (i.e. disease severity) in male patients was higher than female patients. Moreover, several studies have noted that estrogen acts as a protective factor against CAD. In fact, CAD might develop in one-third of men compared to one-fifth of women until the age of $60(17,18)$.

In this study, the number of affected coronary arteries (three coronary arteries) in urban patients was higher than that reported in rural patients. It seems that patterns of urban life and the risk factors affect the severity of CAD. Epidemiological studies have shown that in developing countries, exposure to risk factors for CAD has increased. Globalization, urbanization and behavioral changes are considered as significant contributing factors (19). Moreover, some studies have shown that CAD is two to three times more prevalent in urban population compared to rural population, perhaps due to immobility and urban lifestyle (20).

The results of this study showed that the use of alcohol and drugs was more common in patients with more than one affected coronary vessel. Some studies have introduced alcohol abuse as a risk factor for hypertension and cardiovascular diseases (21). Moreover, Darabian and Abbasi investigated the risk factors for ischemic heart disease. Drug addiction, similar to other cardiovascular risk factors, was noted as an independent risk factor for CAD (22). However, in patients with a higher number of affected vessels, alcohol and drugs may be used to relieve the pain.

The strengths of our study include a large sample size and a comprehensive estimation of the demographic and socioeconomic factors of CAD patients in three treatment groups of CABG, PCI and drug therapy. Also, the results of this study, the first of its kind in Iran, describe a good coverage from multicenteral health cares in Mashhad City, Iran, with the majority of patients having cardiovascular disease. A limitation of our study is that insufficient data from patients' medical records led to have missing data in some cases. This was a missing by natural design; so, we used univariate t-test for generalized estimating equations with missing data.

In conclusion, this study showed that by increasing involvement of coronary arteries, the prevalence of diabetes and hypertension increases in patients. Several studies have introduced diabetes and high-blood pressure as risk factors for CAD, independent of other risk factors. In fact, by a $20-\mathrm{mmHg}$ increase in systolic blood pressure and a $10-\mathrm{mmHg}$ rise in diastolic blood pressure, the risk of CAD-related mortality is doubled (23). Based on stud- 
ies on diabetic patients, reduced low-density lipoprotein and increased high-density lipoprotein are among the risk factors for the atherosclerotic process (17).

Based on the current results, although the treatment choice is influenced by disease severity, type of occlusion, urgency of treatment, clinical diagnosis, and patient's preference, hospital facilities and patient's economic status are also highly influential. In other words, treatment method is selected based on disease severity, clinical diagnosis, patient's preference and socioeconomic constraints and requirements. It can be also concluded that risk factors for CAD such as gender, lifestyle, smoking, alcohol abuse, diabetes and hypertension are not only correlated with the incidence of $C A D$, but also significantly associated with the severity of this condition.

\section{Acknowledgements}

We would like to thank the research deputy of Mashhad University of Medical Sciences for their support. We also appreciate Javad-Al-Aemeh Cardiovascular Hospital for their valuable cooperation.

\section{Authors' Contributions}

Study concept and design: Mohammad Khajedaluee, Maryam Mirzaie, Homa Falsoleiman; Analysis and interpretation of data: Mohammad Khajedaluee, Maryam Mirzaie; Drafting of the manuscript: Mehdi Reza Emadzadeh, and Asadollah Mirzaie.

\section{References}

1. Yaghoubi A, Tabrizi JS, Mirinazhad MM, Azami S, Naghavi-Behzad M, Ghojazadeh M. Quality of life in cardiovascular patients in iran and factors affecting it: a systematic review. J Cardiovasc Thorac Res. 2012;4(4):95-101.

2. Lee IM, Shiroma EJ, Lobelo F, Puska P, Blair SN, Katzmarzyk PT, et al. Effect of physical inactivity on major non-communicable diseases worldwide: an analysis of burden of disease and life expectancy. Lancet. 2012;380(9838):219-29.

3. Mejean C, Droomers M, van der Schouw YT, Sluijs I, Czernichow S, Grobbee DE, et al. The contribution of diet and lifestyle to socioeconomic inequalities in cardiovascular morbidity and mortality. Int J Cardiol. 2013;168(6):5190-5.

4. Hatmi ZN, Tahvildari S, Gafarzadeh Motlag A, Sabouri Kashani A Prevalence of coronary artery disease risk factors in Iran: a population based survey. BMC Cardiovasc Disord. 2007;7:32.

5. Clark AM, DesMeules M, Luo W, Duncan AS, Wielgosz A. Socioeconomic status and cardiovascular disease: risks and implications for care. Nat Rev Cardiol. 2009;6(11):712-22.

6. Beaglehole R, Yach D. Globalisation and the prevention and con- trol of non-communicable disease: the neglected chronic diseases of adults. Lancet. 2003;362(9387):903-8.

7. Ford I, Robertson M, Komajda M, Bohm M, Borer JS, Tavazzi L, et al. Top ten risk factors for morbidity and mortality in patients with chronic systolic heart failure and elevated heart rate: The SHIFT Risk Model. Int J Cardiol. 2015;184:163-9.

8. Hlatky MA, Boothroyd DB, Bravata DM, Boersma E, Booth J, Brooks MM, et al. Coronary artery bypass surgery compared with percutaneous coronary interventions for multivessel disease: a collaborative analysis of individual patient data from ten randomised trials. Lancet. 2009;373(9670):1190-7.

9. Sjogren J, Thulin LI. Quality of life in the very elderly after cardiac surgery: a comparison of SF-36 between long-term survivors and an age-matched population. Gerontology. 2004;50(6):407-10.

10. Davey Smith G, Hart C, Hole D, MacKinnon P, Gillis C, Watt G, et al. Education and occupational social class: which is the more important indicator of mortality risk? J Epidemiol Community Health.1998;52(3):153-60.

11. Federman AD, Adams AS, Ross-Degnan D, Soumerai SB, Ayanian JZ. Supplemental insurance and use of effective cardiovascular drugs among elderly medicare beneficiaries with coronary heart disease. JAMA. 2001;286(14):1732-9.

12. Braun LT, Davidson MH. Cholesterol-lowering drugs bring benefits to high-risk populations even when LDL is normal. J Cardiovasc Nurs. 2003;18(1):44-9.

13. Jahangiri H, Norouzi A, Dadsetan P, Sarabi G. Determine the prevalence of coronary artery disease (CAD) risk factors in depressed retired population. Life Sci J. 2013;10(3):327-34.

14. Beckman JA, Creager MA, Libby P. Diabetes and atherosclerosis: epidemiology, pathophysiology, and management. JAMA. 2002;287(19):2570-81.

15. Turner RC, Millns H, Neil HA, Stratton IM, Manley SE, Matthews $\mathrm{DR}$, et al. Risk factors for coronary artery disease in non-insulin dependent diabetes mellitus: United Kingdom Prospective Diabetes Study (UKPDS: 23). BMJ. 1998;316(7134):823-8.

16. Kanitz MG, Giovannucci SJ, Jones JS, Mott M. Myocardial infarction in young adults: risk factors and clinical features. J Emerg Med.1996;14(2):139-45.

17. Ben Mansour N, Lassoued O, Saidi O, Aissi W, Ben Ali S, Ben Rom dhane H. Trends in secondary prevention of coronary heart disease in Tunisia: prevention of recurrences of MI and stroke. Glob Heart. 2012;7(4):361-6.

18. Ambrose JA, Singh M. Pathophysiology of coronary artery disease leading to acute coronary syndromes. F100oPrime Rep. 2015;7:08.

19. Okrainec K, Banerjee DK, Eisenberg MJ. Coronary artery disease in the developing world. Am Heart J. 2004;148(1):7-15.

20. Singh RB, Sharma JP, Rastogi V, Raghuvanshi RS, Moshiri M, Verma SP, et al. Prevalence of coronary artery disease and coronary risk factors in rural and urban populations of north India. Eur Heart J.1997;18(11):1728-35.

21. Kurihara O, Takano M, Seino Y, Shimizu W, Mizuno K. Coronary atherosclerosis is already ongoing in pre-diabetic status: Insight from intravascular imaging modalities. World J Diabetes. 2015;6(1):184-91.

22. Darabian S, Abbasi A. The correlation of ischemic risk factors with left main tract disease. KAUMS J (FEYZ). 2007;11(3):31-5.

23. Chobanian AV, Bakris GL, Black HR, Cushman WC, Green LA, Izzo JJ, et al. Seventh report of the Joint National Committee on Prevention, Detection, Evaluation, and Treatment of High Blood Pressure. Hypertension. 2003;42(6):1206-52. 